\title{
PEMBELAJARAN MATEMATIKA MELALUI BLENDED LEARNING BERBASIS MULTI APLIKASI SEBAGAI STRATEGI MENGHADAPI ERA REVOLUSI INDUSTRI 4.0
}

\author{
Desy Arnita Dewi ${ }^{1}$
}

\author{
1. MAN Negeri 2 Banjarmasin
}

desyarnitadewi@gmail.com

\begin{abstract}
ABSTRAK
Kemajuan ilmu pengetahuan serta teknologi informasi dan komunikasi sebagai salah satu produk perubahan zaman banyak membawa dampak positif bagi kemajuan dunia pendidikan sekarang ini. Era digitalisasi yang disebut era revolusi industri 4.0 membuat perubahan yang sangat cepat. Banyak aplikasi pembelajaran digital yang bisa digunakan secara efektif dan efisien sebagai media penunjang pembelajaran. Diantaranya GeoGebra, Google Classroom, dan Quizizz. Aplikasi tersebut dapat berdiri sendiri, ataupun dikombinasikan satu sama lain sesuai kebutuhan. Keterlibatan suatu proses perkembangan teknologi yang diaplikasikan dalam proses pembelajaran disebut $e$ learning. Pembelajaran yang mengkombinasikan atau mencampurkan pembelajaran tatap muka dan pembelajaran berbasis e-learning disebut sebagai Blended Learning. Penelitian ini dirancang dan dilaksanakan menggunakan Penelitian Tindakan Kelas sebanyak dua siklus. Subjek dalam penelitian ini adalah siswa kelas XII MIPA 1 MAN 2 Model Banjarmasin tahun pelajaran 2019/2020 yang berjumlah 35 siswa. Objek penelitian adalah aktivitas dan hasil belajar siswa pada materi turunan fungsi trigonometri. Teknik pengumpulan data menggunakan teknik observasi, tes dan dokumentasi. Hasil penelitian menunjukkan siswa berada dalam kualifikasi aktif dan terdapat peningkatan rata-rata hasil belajar siswa dari siklus I ke siklus II.
\end{abstract}

Kata Kunci: Blended Learning, GeoGebra, Google Classroom, Quizizz

\section{PENDAHULUAN}

\section{A. Latar Belakang}

Kualitas pendidikan di Indonesia masih relatif rendah dibandingkan negara-negara lain. Hal ini berdasarkan data yang diambil dari laman kemdikbud bahwa capaian nilai Programme for International Student Assesment (PISA) tahun 2015 masih menempatkan Indonesia diperingkat 10 terbawah. Oleh karena itu, diperlukan terobosan terus menerus agar pendidikan di Indonesia bisa lebih baik perkembangannya.

Kemajuan ilmu pengetahuan, teknologi informasi dan komunikasi yang demikian cepat diharapkan membawa dampak positif bagi kemajuan dunia pendidikan sekarang ini. Era digitalisasi yang sekarang lebih tren disebut era revolusi industri 4.0 , telah merambah ke berbagai sektor temasuk pendidikan. Hal ini dapat menjadi media yang sangat efektif dan efisien untuk digunakan sebagai penunjang proses pembelajaran. Beragam fasilitas multimedia berbasis IT dapat dimanfaatkan agar proses pembelajaran menjadi lebih menarik. Berbagai aplikasi pembelajaran menarik baik gratis maupun berbayar sudah tersedia untuk bisa dimanfaatkan maksimal bagi generasi milenial. 
Pendekatan scientific yang dominan dipakai pada Kurikulum 2013 menjadikan perubahan paradigma pembelajaran menjadi yang semula berpusat pada guru (teacher centered approach) menjadi berpusat pada siswa (student centered approach). Guru sebagai ujung tombak dunia pendidikan dituntut harus bisa menyesuaikan diri dengan perkembangan jaman. Siswa sekarang terutama di perkotaan rata-rata sudah sangat familiar dengan teknologi. Dari pengalaman penulis bahwa dari seluruh siswa di Madrasah Aliyah Negeri 2 Banjarmasin hanya beberapa orang yang belum memiliki fasilitas smartphone. Disamping itu, madrasah sudah memiliki beberapa ruangan dan area yang bisa mengakses internet secara gratis. Sehingga, memungkinkan memanfaatkan teknologi informasi dan komunikasi saat proses pembelajaran agar siswa bisa lebih aktif, interaktif dan menghasilkan prestasi belajar yang lebih baik.

Matematika selama ini masih dianggap sebagai mata pelajaran sulit bagi sebagian siswa. Hal ini menyebabkan rendahnya motivasi, minat dan hasil belajar mereka. Pembelajaran matematika seharusnya bisa menyesuaikan kebutuhan jaman, memanfaatkan teknologi di era revolusi industri 4.0 sebagai strategi agar pembelajaran menjadi lebih menarik, aktif dan interaktif. Berdasarkan latar belakang tersebut, penulis tertarik menulis penelitian dengan judul: "Pembelajaran Matematika melalui Blended Learning Berbasis Multi Aplikasi sebagai Strategi Menghadapi Era Revolusi Industri 4.0".

\section{B. Rumusan Masalah}

Berdasarkan latar belakang masalah yang dikemukakan di atas maka rumusan masalah dalam penelitian ini adalah sebagai berikut.

1) Bagaimana aktivitas siswa dalam pembelajaran matematika melalui Blended Learning berbasis Multi Aplikasi?

2) Apakah ada peningkatan rata-rata hasil belajar siswa dalam pembelajaran matematika melalui Blended Learning berbasis Multi Aplikasi?

\section{Tujuan Penelitian}

Tujuan diadakannya penelitian ini adalah untuk mengetahui:

1) Aktivitas siswa dalam pembelajaran matematika melalui Blended Learning berbasis Multi Aplikasi.

2) Rata-rata hasil belajar siswa dalam pembelajaran matematika melalui Blended Learning berbasis Multi Aplikasi.

\section{METODE PENELITIAN}

Penelitian ini termasuk jenis Penelitian Tindakan Kelas (PTK). Menurut Arikunto dkk (2008), PTK adalah penelitian tindakan (action research) yang dilakukan dengan tujuan memperbaiki mutu praktik pembelajaran di kelas. Penelitian ini dilaksanakan semester ganjil tahun pelajaran 2019/2020 di kelas XII MIPA 1 MAN 2 Model Banjarmasin. Objek penelitian adalah aktivitas dan hasil belajar siswa pada pokok bahasan Turunan Fungsi Trigonometri. Teknik pengumpulan data melalui observasi, tes dan dokumentasi. Teknik analisis data perihal aktivitas siswa dan hasil belajar siswa, dengan dua cara berbeda. Aktivitas siswa dihitung persentase per aspek aktivitas yang di amati kemudian dikualifikasikan berdasarkan tabel berikut. 
Tabel 1. Kriteria interpretasi skor

\begin{tabular}{|c|l|}
\hline Persentase (\%) & Kualifikasi \\
\hline $0-<21$ & Sangat tidak aktif \\
\hline $21-<41$ & Tidak aktif \\
\hline $41-<61$ & Cukup aktif \\
\hline $61-<81$ & Aktif \\
\hline $81-\leq 100$ & Sangat aktif \\
\hline
\end{tabular}

(Adaptasi Riduwan, 2013)

Selanjutnya, untuk menarik kesimpulan digunakan modus, yaitu melihat kualifikasi aktivitas siswa yang terbanyak. Sedangkan, untuk penilaian hasil belajar dalam penelitian ini dilakukan per butir soal jika jawaban siswa benar diberi skor 1 dan jika jawaban siswa salah diberi skor 0 . Kemudian dicari rata-rata kelas dan persentase ketuntasan secara klasikal yang berpedoman pada KKM satuan pendidikan yaitu 75 .

Tabel 2. Kualifikasi hasil belajar siswa

\begin{tabular}{|c|c|}
\hline Nilai & Huruf \\
\hline$\geq 75$ & Tuntas \\
\hline$<75$ & Tidak Tuntas \\
\hline
\end{tabular}

Untuk mengetahui keberhasilan penelitian ini maka peneliti menentukan kriteria keberhasilan apabila aktivitas siswa secara keseluruhan berada pada kualifikasi minimal aktif dan rata-rata kelas memenuhi KKM.

\section{HASIL DAN PEMBAHASAN}

Berdasarkan pengalaman penulis banyak siswa MAN 2 Banjarmasin mengalami kesulitan menggambar titik dan garis pada bidang koordinat apalagi menggambar grafik fungsi, khususnya fungsi trigonometri. Hal tersebut menyebabkan banyak waktu tersita, sehingga tujuan pembelajaran sulit tercapai. Karena itu penting adanya media yang bisa membangkitkan minat dan motivasi siswa dalam mempelajari hal tersebut, sehingga siswa menjadi mudah paham. Dengan bantuan aplikasi GeoGebra, siswa dapat dengan mudah melakukan pengamatan, melakukan eksplorasi, menemukan pola-pola, menerapkan konsep sebelumnya yang dikuasai pada konteks yang baru, dan memverifikasi hasil sehingga belajar siswa lebih bermakna.

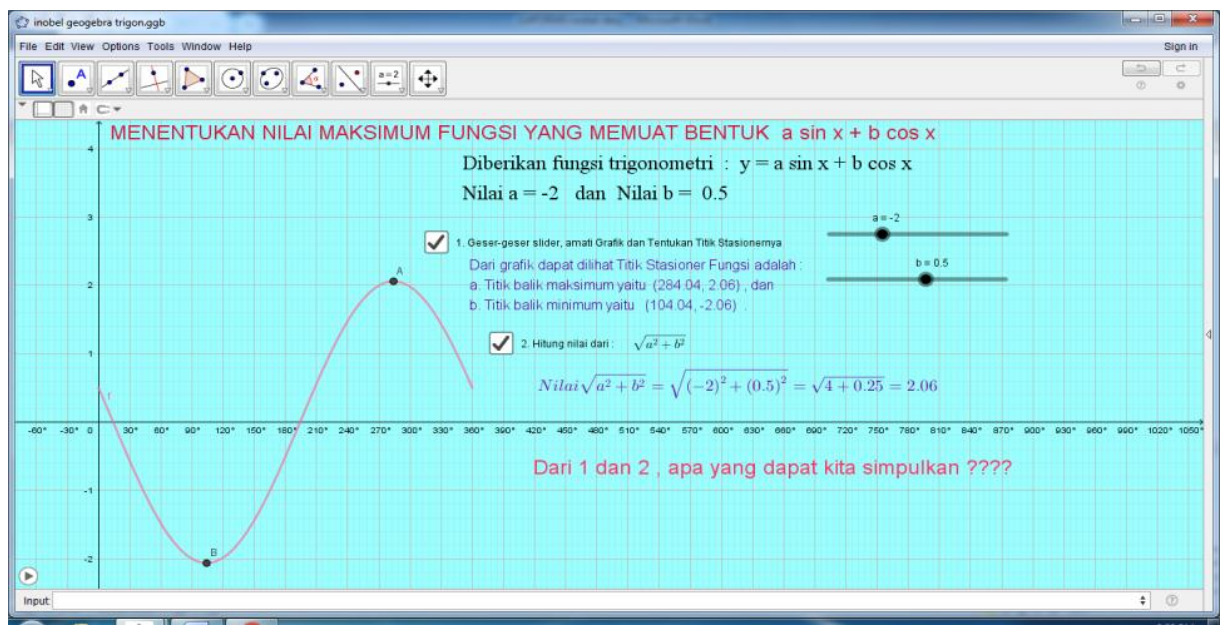

Gambar 1. Screenshoot media yang dibuat dengan aplikasi Geogebra 


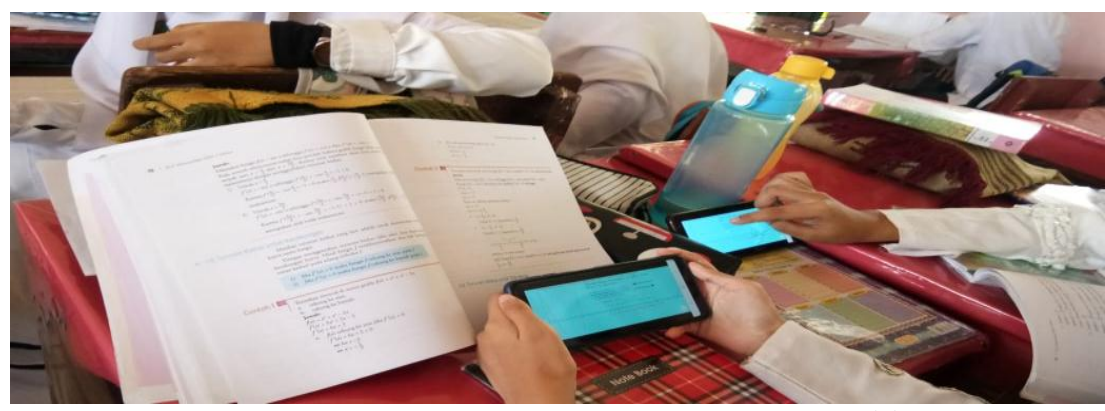

Gambar 2. Siswa belajar dari media yang dibuat pada aplikasi GeoGebra

Saat proses pembelajaran,dilakukan pengamatan terhadap aktivitas siswa dengan mengisi lembar observasi siswa. Observer dalam hal ini adalah mahasiswa yang sedang praktik lapangan (PPL). Data selengkapnya mengenai hasil observasi aktivitas siswa dapat dilihat pada tabel berikut:

Tabel 3. Hasil Observasi Aktivitas Siswa Per Siklus

\begin{tabular}{|c|c|c|c|c|c|}
\hline \multirow[b]{2}{*}{ No } & \multirow{2}{*}{ Aspek yang diamati } & \multicolumn{2}{|c|}{ Siklus I } & \multicolumn{2}{|c|}{ Siklus II } \\
\hline & & $\mathrm{P}(\%)$ & $\mathrm{K}$ & $\mathrm{P}(\%)$ & $\mathrm{K}$ \\
\hline 1. & Siswa mengkomunikasikan ide/ gagasannya. & 58 & $\mathrm{CA}$ & 61 & A \\
\hline 2. & $\begin{array}{c}\text { Siswa mengajukan pertanyaan yang berkaitan } \\
\text { dengan materi pelajaran. }\end{array}$ & 54 & CA & 55 & CA \\
\hline 3. & $\begin{array}{c}\text { Siswa bekerjasama mengerjakan Lembar } \\
\text { Aktivitas }\end{array}$ & 78 & A & 83 & A \\
\hline 4. & Siswa memanfaatkan media (Aplikasi) & 76 & A & 84 & SA \\
\hline 5. & Siswa mempresentasikan hasil diskusi/tugas. & 67 & A & 80 & A \\
\hline 6. & Siswa terlibat menyimpulkan pelajaran & 75 & A & 79 & A \\
\hline
\end{tabular}

Keterangan: $\mathrm{K}:$ Kualitas

$\begin{array}{ll}\text { CA : Cukup Aktif } & \text { A : Aktif } \\ \text { TA : Tidak aktif } & \text { SA : Sangat Aktif }\end{array}$

Berdasarkan modus, kualifikasi aktivitas pada kedua siklus adalah aktif. Sehingga disimpulkan bahwa dengan pembelajaran blended learning berbasis multi aplikasi menunjukkan bahwa aktivitas siswa selama mengikuti kegiatan pembelajaran dari siklus I ke siklus II secara keseluruhan berada pada kualifikasi aktif.

Penerapan pembelajaran yang memadukan pembelajaran berbasis $e$ learning dengan pembelajaran tatap muka melalui perencanaan yang matang dengan memperhatikan komponen-komponen dan aspek-aspek pembelajaran dapat mendorong peningkatan aktivitas siswa. Dengan menggunakan blended learning maka pembelajaran mejadi menyenangkan dan siswa termotivasi untuk aktif dalam pembelajaran.

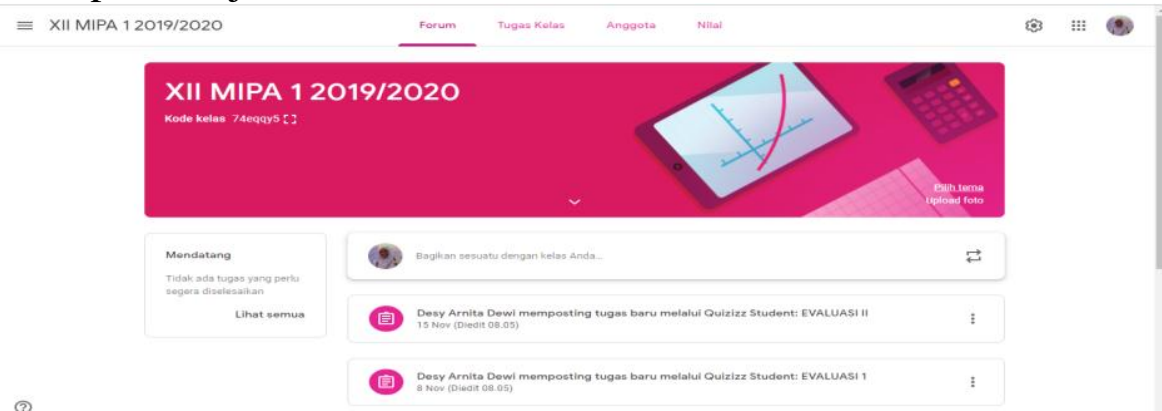

Gambar 3. Screenshoot tautan tugas Quizizz di Google Classroom 
Setelah dilakukan pembelajaran menggunakan blended learning berbantuan software geogebra maka dilakukan evaluasi akhir siklus dengan aplikasi Quizizz yang terhubung melalui kelas yang ada di Google Classroom.

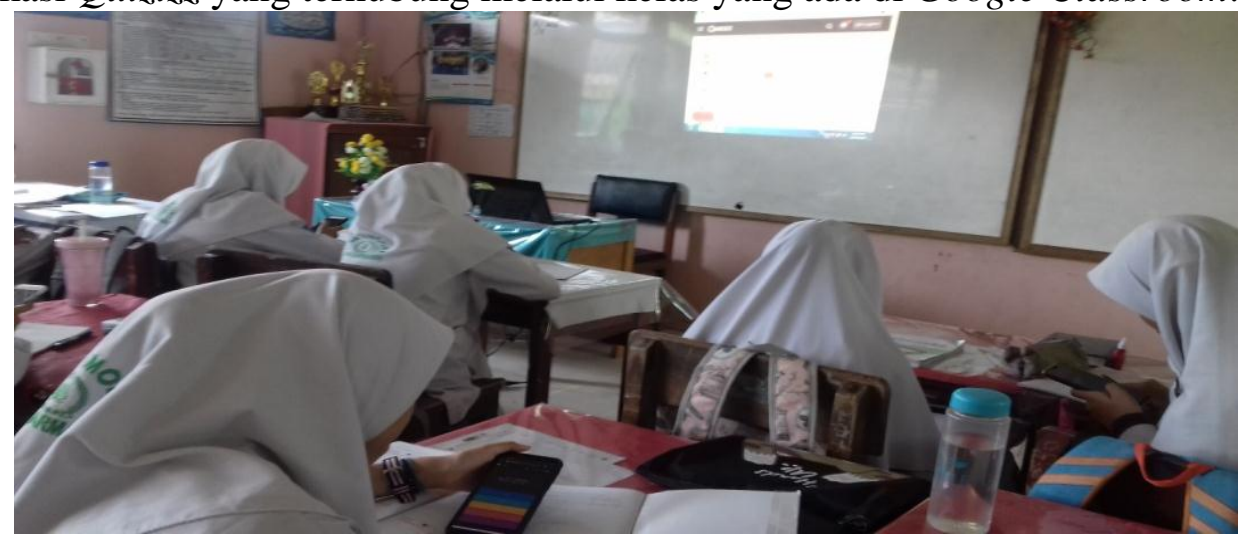

Gambar 4. Siswa mengerjakan soal evaluasi menggunakan aplikasi Quizizz

Hasil belajar siswa pada evaluasi yang telah dilaksanakan dapat dilihat secara langsung melalui aplikasi Quizizz yang tampilan laporannya sebagai berikut.

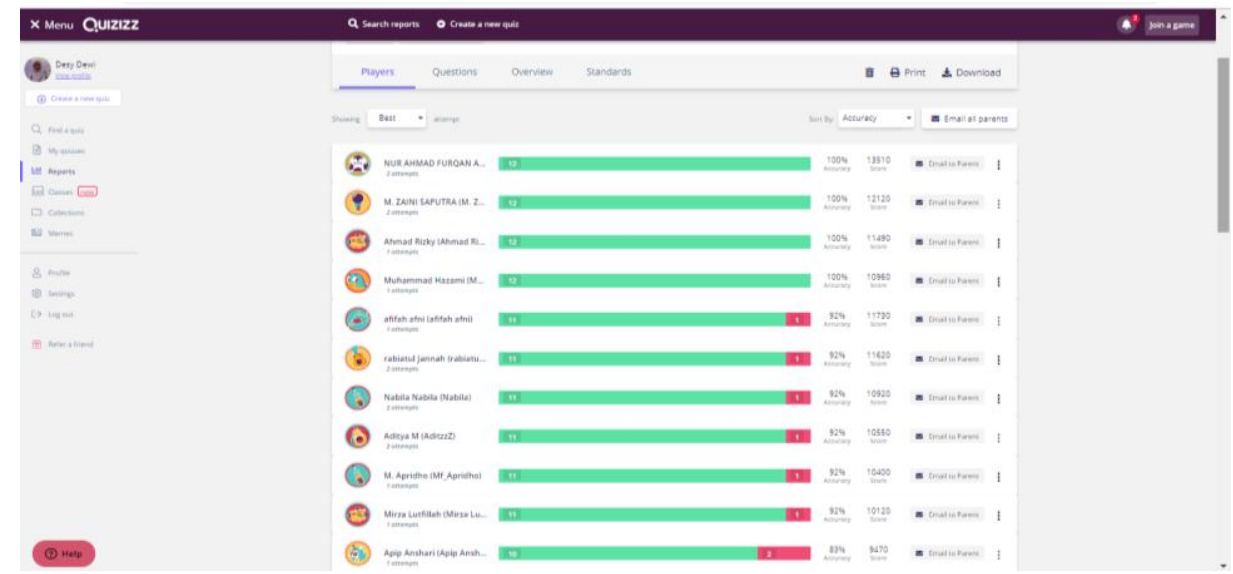

Gambar 5. Laporan hasil evaluasi yang ada pada aplikasi Quizizz

Hasil belajar siswa setelah pembelajaran, secara klasikal dapat dilihat pada tabel berikut.

Tabel 4. Persentase Ketuntasan Siswa Per Siklus

\begin{tabular}{|l|c|c|c|c|c|}
\hline \multirow{2}{*}{ Nilai } & Kriteria & Frekuensi & Persentase & Frekuensi & Persentase \\
\cline { 3 - 6 }$\geq 75$ & Tuntas & 24 & $77,14 \%$ & 31 & $88,57 \%$ \\
\hline$<75$ & $\begin{array}{c}\text { Tidak } \\
\text { Tuntas }\end{array}$ & 11 & $22,86 \%$ & 4 & $11,43 \%$ \\
\hline Jumlah & 35 & $100 \%$ & 35 & $100 \%$ \\
\hline \multicolumn{2}{|c|}{ Rata-rata kelas } & 73,71 & \multicolumn{2}{c|}{81,71} \\
\hline
\end{tabular}

Mengacu pada indikator keberhasilan penelitian yang telah ditetapkan maka dapat dinyatakan bahwa persentase ketuntasan secara klasikal pada siklus I sudah memenuhi indikator yaitu 77,14\% namun rata-rata kelas yaitu 73,71 masih belum mencapai KKM satuan pendidikan. Setelah dilaksanakan siklus II, hasil 
rata-rata kelas adalah 81,71 sudah mencapai KKM dan secara keseluruhan terjadi peningkatan persentase ketuntasan menjadi 88,57\%. Dari hasil tersebut maka indikator keberhasilan penelitian sudah tercapai.

\section{PENUTUP} bahwa:

Berdasarkan hasil penelitian yang telah dilakukan dapat disimpulkan

(1) Aktivitas siswa dalam pembelajaran matematika melalui Blended Learning berbasis Multi Aplikasi berada pada kualifikasi aktif.

(2) Terdapat peningkatan rata-rata hasil belajar siswa dalam pembelajaran matematika melalui Blended Learning berbasis Multi Aplikasi.

Setelah penelitian ini dilakukan, maka terbuka bagi para peneliti lain yang ingin mengembangkan penelitian ini pada lingkup materi yang lebih luas. Guru bisa memanfaatkan kemajuan ilmu pengetahuan, teknologi dan komunikasi dengan memanfaatkan beragam aplikasi (multi aplikasi) sebagai salah satu strategi menghadapi era revolusi industri 4.0. Hal ini bertujuan meningkatkan aktivitas dan hasil belajar siswa menjadi lebih baik. Pada dampak yang lebih luas diharapkan membawa kemajuan pada dunia pendidikan secara umum.

\section{DAFTAR PUSTAKA}

Arikunto, S., Suhardjono, \& Supardi. (2008). Penelitian Tindakan Kelas. PT. Bumi aksara. Jakarta

Husamah. (2014). Pembelajaran Bauran (Blended Learning). Jakarta:Prestasi Pustaka.

Kunandar. (2012). Langkah Mudah Penelitian Tindakan Kelas. Jakarta: PT RajaGrafindo Persada.

Kunandar. (2014). Penelitian Autentik (Penilaian Hasil Belajar Peserta Didik Berdasarkan Kurikulum 2013). Jakarta: PT RajaGrafindo Persada.

Kemendikbud. (2013). Lampiran Permendikbud nomor 65 Tahun 2013 tentang Standar Proses Pendidikan Dasar dan Menengah. Jakarta.

Kemendikbud. (2014). Lampiran Permendikbud No 104 Tahun 2014 tentang Penilaian Hasil Belajar oleh pendidik pada Pendidikan Dasar dan Pendidikan Menengah. Jakarta.

Riduwan. (2013). Belajar Mudah Penelitian. Bandung: Alfabeta

Rohman, Moch. Fatkoer. (2014). Panduan Penggunaan GeoGebra Software Alat Bantu Pembelajaran Matematika.

Syarif, Izzuddin. (2012). Pengaruh Model Blended Learning terhadap Motivasi dan Prestasi Belajar Siswa SMK. Jurnal Pendidikan Vokasi, Vol 2, Nomor 2. Online. http://journal.uny.ac.id Diakses tanggal 6 November 2019

Sindu, Partha. Santyasa. Sukra Warpala. (2013). Pengaruh Model E-Learning Berbasis Masalah dan Motivasi Belajar Terhadap Hasil Belajar KKPI Siswa Kelas $\mathrm{X}$ di MAN Negeri 2 Singaraja. e-Journal Program Pascasarjana Universitas Pendidikan Ganesha http://pasca.undiksha.ac.id/e-journal/index.php/jurnal_tp/article/view/617 Diakses tanggal 6 November 2019

Sutikno, Sobry. (2009). Belajar dan Pembelajaran. Bandung: Prospect.

Yusuf, M. (2011). Mengenal Blended Learning. Jurnal Lentera Pendidikan. 